\title{
A Cross-Country Nonparametric Analysis of Bahrains Banking System
}

\author{
David Grigorian \\ International Monetary Fund \\ email: dgrigorian@imf .org
}

\author{
Vlad Manole \\ Rutgers University \\ email: vm286@andromeda.rutgers.edu
}

\begin{abstract}
Bahrains financial sector development strategy succeeded in building a leading regional banking center, which has become one of the main engines of growth and sources of employment. Based on banklevel productivity estimates obtained using non-parametric estimation, the paper concludes that Bahrain continues to occupy a front-runner position among sample GCC countries. Results also reveal that: (i) banks in Bahrain still lag behind their Singaporean counterparts (included in the study as a benchmark), and (ii) there is strong competition from other countries in the region. The results appear to be robust with respect to changes in the sample size and model specifications.
\end{abstract}

\section{Introduction}

The banking sector in Bahrain has grown rapidly in recent years, becoming one of the main engines of growth and sources of employment. This expansion was facilitated by rapid regional growth and the need to intermediate the substantial regional oil-related capital flows. While Bahrains financial sector development strategy succeeded in building a leading regional banking center, there have been constant challenges on the way. External shockssuch as the uncertainties related to international oil markets, regional instability, and volatility in the international financial marketshave tested Bahrains financial sector. Competition from other GCC countries has put pressure on

JEL Classification: C14, G21

Key words and phrases: Data Envelopment Analysis, banking efficiency, Bahrain 
the Bahraini financial industry to develop new products and instruments. The development of the financial sector in the region during recent years has been characterized by a significant build-up of capacity in various regional financial centers, including Bahrain, but also Dubai, Qatar, Kuwait and Riyadh. While these centers in part serve the domestic market, the size of that market is less than 35 million people, requiring these centers to specialize in particular services for the international markets. For example, looking at each of the centers strengthsfor example, Bahrain on Islamic Finance, Qatar on Project Financing, Kuwait on Asset Management, Dubai on Investment Banking niche products could be developed to offer services globally ${ }^{1}$.

The motivation behind the paper is straightforward: it attempts to assess the performance of the banking sector in Bahrain through a comparison with banks in the region and Singapore, a major Asian financial center. Such an assessment of efficiency and competitiveness (within regional and international contexts) can be important for a future reform agenda in Bahrain. This paper looks beyond the conventional measures of performance of banks. In doing so, it compares the efficiency indicators of banks in Bahrain with that of their counterparts in Kuwait, Qatar, the United Arab Emirates, and Singapore, obtained by using a nonparametric estimation method called Data Envelopment Analysis (DEA). The DEA is a linear programming technique that constructs an efficiency frontier based on best performing banks, which is then used to assess the relative performance of other banks. One of the main advantages of this methodology is that it does not impose any functional forms and/or assumptions on the structure of the banks objective function or the error term. As a result, it allows one to model other functions performed by the banksapart from production of loanssuch as liquidity and services provision. By treating every bank as a single decision-making entity, the paper defines a set of inputs and outputs and uses the most recent data to arrive at overall efficiency indexes for the sample banks. It then decomposes these indexes between purely technical and scale-related, thus offering additional insights with policy relevance. The data used in the paper is obtained through BankScope database, and in the case of Bahrain, also contains updates and additions from the Bahrain Monetary Agency (BMA).

\footnotetext{
${ }^{1}$ For more information on the structure of the banking sectors in the Gulf region, see van Ark et al, 2008 and Al-Hassan et al, 2010.
} 


\section{Methodology}

During the past few decades, banking sectors around the world experienced profound regulatory and technological changes. Advanced applications in computer and communications technology, together with the introduction of new financial instruments, have significantly modified the technology of bank production and efficiency. This subsequently altered the way economists look at the functions performed by the banks and measure their efficiency. One of the methods used in the literature to evaluate productivity and performance of banks is the Data Envelopment Analysis, a nonparametric method that allows one to account for a wide range of functions performed by banks. This method compares relative performance of decision-making units (DMU)in this case, banksby building a frontier comprised of the most efficient DMUs and focusing on how close other DMUs are to this frontier.

The method was first proposed by Farrell (1957), who suggested constructing the frontier as a piece-wise linear combination of the most efficient units. He also defined the most efficient DMUs to be those for which no other DMU or a linear combination of DMUs has as much or more of every output (given a fixed amount of inputs, for an output-oriented model) or as little or less of every input (given a fixed amount of outputs, for an input-oriented model). The efficiency frontier formed by connecting these best practice observations would yield a convex production possibility set. The DMUs falling inside the frontier are termed inefficient, and their performance would be measured visà-vis the frontier DMUs. Thus this method provides a measure of relative efficiency. In practice, DEA was first implemented by Charnes, Cooper, and Rhodes (1978), who used a linear-programming method to identify the efficient DMUs and coined the term Data Envelopment Analysis (DEA). ${ }^{2}$

Data Envelopment Analysis was used extensively in studies of banking industry in developed market economies. On U.S. data alone the method was used in more than 30 published articles ${ }^{3}$. The method was also applied for Norway, Spain, U.K., and several other countries ${ }^{4}$. There is a vast literature that uses Data Envelopment Analysis for inter-countries comparisons ${ }^{5}$. The

\footnotetext{
${ }^{2}$ Their method is based on the assumption that the production units have constant returns to scale. Banker, Charnes, and Cooper (1984) later relaxed the assumption and proposed a model with units of production with variable returns to scale. Theoretical extensions of these methods and empirical applications are discussed in Cook and Zhu (2005), Cooper, Seiford, and Zhu (2004) and surveyed in Murillo-Zamorano (2004).

${ }^{3}$ See Alam (2001), Wheelock and Wilson, (1999).

${ }^{4}$ See Berger and Humphrey (1997) for a detailed survey.

${ }^{5}$ We mention just studies by Bergendhal (1998), Bukh et al. (1995) and Berg et al. (1993)
} 
integration effort of European Union countries is analyzed by several studies like Casu and Molyneux, (2003) that finds relatively small improvement in bank efficiency levels and no convergence after 1992 or Lozano-Vivas, Pastor and Iftekhar, (2001) that identifies Spain, Denmark and Portugal with the most efficient banking sector in European Union. Two papers analyzing Central and Eastern European countries, find that the efficiency of their banking sector is correlated with the level of integration in European Union (Grigorian and Manole, 2006 and Stavarek 2006).

The banking sector from developing countries is also examined with the help of DEA. For India and Pakistan, economic reforms tend to increase the efficiency of the banking system (Ataullah, A., and Le, H., 2006, and Ataullah, A.,Cockerill, T. and Le, H., 2004). Financial liberalization in the 1980s increased bank efficiency in Turkey (Isik and Hassan, 2003) and financial crises affected the efficiency in the second half of the 1990s (Ozkan-Gunay and Tektas 2006). Closer to the region analyzed in this paper, Limam, (2001) studies the technical efficiency of GCCs banks in 1999. He finds that Bahrain and Saudi Arabia have the most efficient banks and that a larger bank size is associated with better efficiency. Several country studies from the region examine the effect of financial reforms. Maghyereh, (2004) shows that financial liberalization in Jordan increased the efficiency of the banking sector. For Kuwait, Saad and EL Moussawi, (2006) examines banks efficiency in a period of structural reforms.

To arrive at basic specification of a linear-programming model underlying the DEA, we assume that there are $\mathrm{K}$ inputs and $M$ outputs for every DMU. For the $i^{\text {th }}$ DMU the inputs and outputs are represented by vectors $x_{i}$ and $y_{i}$, respectively. For each DMU the method aims to obtain a measure of the ratio of all outputs over all inputs, such as $u_{i}{ }^{\prime} y_{i} / v_{i}{ }^{\prime} x_{i}$, where $u_{i}$ and $v_{i}$ are vectors of weights. To select the optimal weights, the following linear-programming

for Nordic countries. In a broader context Pastor et al. (1994), applied DEA for 427 banks from 8 developed countries. Also see the Berger and Humphrey (1997) survey. 
problem is typically proposed:

$$
\begin{aligned}
\max _{u_{i k}, v_{i m}} \frac{u_{i}{ }^{\prime} y_{i}}{v_{i}{ }^{\prime} x_{i}} & \\
\text { s.t. } & \frac{u_{i}^{\prime} y_{j}}{v_{i}{ }^{\prime} x_{j}} \leq 1 \\
& u_{i k}, v_{i m} \geq 0 \\
& i, j=1,2, \ldots N \\
& k=1,2, \ldots K \\
& m=1,2, \ldots M
\end{aligned}
$$

A problem with this formulation is that it has an infinite number of solutions. This can be avoided by introducing a constraint $\nu_{i}{ }^{\prime} x_{i}=1$, and obtaining the multiplier form of the linear programming problem:

$$
\begin{aligned}
\max _{\mu_{i k}, \sigma_{i m}} \mu_{i}{ }^{\prime} y_{i} & \\
\text { s.t. } & \sigma_{i}{ }^{\prime} x_{i}=1 \\
& \mu_{i}{ }^{\prime} y_{j}-\sigma_{i}{ }^{\prime} x_{j} \leq 0 \\
& \mu_{i k}, \sigma_{i m} \geq 0 \\
& i, j=1,2, \ldots N \\
& k=1,2, \ldots K \\
& m=1,2, \ldots M
\end{aligned}
$$

where vectors $u_{i}$ and $v_{i}$ are replaced with $\mu_{i}$ and $\sigma_{i}$. Using the duality property of this linear programming problem, Charnes, Cooper, and Rhodes (1978) derive an equivalent envelopment form as:

$$
\begin{aligned}
\min _{\theta, \lambda} \theta_{i} & \\
\text { s.t. } & -y_{i}+Y \lambda_{i} \geq 0 \\
& \theta_{i} x_{i}-X \lambda_{i} \geq 0 \\
& \lambda_{\text {in }} \geq 0
\end{aligned}
$$

where $\lambda$ is an $(N \times 1)$ vector; and $\theta, \in[0.1]$ a scalar, is the efficiency score for the $i^{\text {th }}$ DMU. ${ }^{6}$ Essentially, $\theta_{i}$ is an indicator of how close a bank is to the

\footnotetext{
${ }^{6} \mathrm{X}=\left[\mathrm{X}_{1}, \ldots, \mathrm{X}_{\mathrm{N}}\right]$ is a $(\mathrm{K} \times \mathrm{N})$ input matrix with columns $\mathrm{X}_{\mathrm{i}}$ and $\mathrm{Y}=\left[\mathrm{y}_{1}, \ldots, \mathrm{y}_{\mathrm{n}}\right]$ is a $(\mathrm{M} \times \mathrm{N})$ column output matrix with columns $\mathrm{y}_{\mathrm{i}}$.
} 
efficiency frontier, with $\theta_{i}<1$ implying that the bank is inside the frontier (i.e., it is an inefficient bank), while $\theta_{i}=1$ implying that the bank is on the frontier (i.e., it is an efficient bank). Due to a fewer number of constraints, the formulation presented in equation 3 is typically used for computations.

The efficiency indexes calculated in such a way are termed overall technical efficiency (OTE) indexes. These can subsequently be decomposed into pure technical efficiency (PTE) and scale efficiency (SE) indexes, to help identify the source of inefficiency of each DMU in the sample. Skipping the details of the formulation, this relationship could be presented as:

$$
\mathrm{OTE}_{i}=\mathrm{PTE}_{i} \cdot \mathrm{SE}_{\mathrm{i}}
$$

To conceptualize this, note that the PTE index is calculated relative to a frontier characterized by variable returns to scale (i.e., either increasing, decreasing, or constant), while OTE is calculated relative to a frontier characterized by only constant returns to scale. Consequently, the SE index captures the scale efficiency (i.e., due to increasing or decreasing returns to scale), while the PTE index captures nonscale and nonscope inefficiencies. ${ }^{7}$

Following the recent literature and bearing in mind the functions performed by commercial banks, ${ }^{8}$ three inputs to the banking production process are selected for the analysis: (i) personnel expenditures, to proxy for labor input, (ii) fixed assets, to proxy for premises, branch network, and equipment, and (iii) interest expenditures, to proxy for the amount of leveraged funds used in the process of intermediation. Next, we specify the following three outputs, which the above inputs are used to produce: (i) revenues, defined as the sum of interest and non-interest income; (ii) net loans, defined as loans net of loan loss provisions; and (iii) liquid assets, defined as the sum of cash and treasure bill holdings as well as balances with monetary authorities. Holding the outputs and two other inputs constant, the lesser amount of the third input used in the production would imply higher efficiency. Even though profit maximization is not implicitly modeled in equations $1-3$, from the way the inputs and outputs are selected, one could think of the banks objective as conditional or constrained profit maximization. Here the banks can be thought

\footnotetext{
${ }^{7}$ For functional forms as well as definitions of PTE, SE, and inefficiencies of scope, refer to Rezvanian and Mehdian (2002), who utilize the framework developed in Fre, Grosskopf, and Lovell (1985).

${ }^{8}$ There are five widely recognized functions performed by banks: profit maximization, risk management, service provision, intermediation, and utility provision (see, for instance, Bergendahl, 1998).
} 
of as maximizing their revenues subject to a fixed level of costs and other outputs. For a given level of costs, maximizing revenues would be identical to maximizing profits.

\section{Results of efficiency analysis}

\subsection{Baseline Specification}

The analysis presented below is based on publicly available data compiled by BankScope. The set contains comprehensive financial data on a large number of banks from Bahrain, Kuwait, Qatar, the United Arab Emirates, and Singapore, the distribution of which by is shown in Table $1 .{ }^{9}$ For each sample country, the number of available banks represents a vast majority of domestically incorporated commercial banks, both conventional and Islamic. Given the stage of development of the banking sectors in the sample countries, no major issues related to data quality and reporting standards are expected.

The results of DEA analysis by countries using the efficiency indexes estimated from equation 3 , and their subsequent breakdown per equation 4 , is presented in Figure 2. Table 2 reports the number of efficient banks in the sample by country and year. These results are largely consistent with ones expectations of relative performance of sample countries, and shed some light on potential sources of inefficiencies. A number of observations are worth noting in this regard. First of all, as expected, at least when it comes to overall efficiency and pure technical efficiency indexes, Singaporean banks on average appear to be ahead of the curve. Although based on a somewhat different set of inputs and outputs, the results are consistent with those reported by Rezvanian and Mehdian (2002). For the period of 1991-1997, this study finds that the average values of OTE, PTE, and SE indexes are 0.74, 0.86, and 0.87, respectively, for a sample of ten Singaporean banks. Corresponding values based of our sample of 16 banks for 1997-2002 are 0.70, 0.88, and $0.81 .^{10}$

Second, Bahrain appears to be ahead of the GCC sub-group, although there seems to be a tight competition from the United Arab Emirates and Qatar, as

\footnotetext{
${ }^{9}$ As indicated earlier, the set contains 2003 data for four Bahraini banks provided by the BMA.

${ }^{10} \mathrm{An}$ important caveat is in order here. Comparison of the results across these studies should be made with caution given the presence of non-Singaporean banks in our sample. However, the existence of GCC banks in the sample is relevant only to the extent that they are on the efficiency frontier (see Table 2). If all of them were located inside the frontier, they would not have changed the DEA outcome for Singaporean banks, making the comparison across studies more meaningful.
} 
Table 1: Number of Sample Banks by Country, 1997-2003

\begin{tabular}{|c|c|c|}
\hline Country & Year & No. of Banks \\
\hline Bahrain & 1997 & 8 \\
\hline Kuwait & & 5 \\
\hline Qatar & & 2 \\
\hline Singapore & & 14 \\
\hline United Arab Emirates & & 3 \\
\hline Total & & 32 \\
\hline Bahrain & 1998 & 10 \\
\hline Kuwait & & 5 \\
\hline Qatar & & 4 \\
\hline Singapore & & 13 \\
\hline United Arab Emirates & & 10 \\
\hline Total & & 42 \\
\hline Bahrain & 1999 & 9 \\
\hline Kuwait & & 6 \\
\hline Qatar & & 5 \\
\hline Singapore & & 12 \\
\hline United Arab Emirates & & 10 \\
\hline Total & & 42 \\
\hline Bahrain & 2000 & 10 \\
\hline Kuwait & & 6 \\
\hline Qatar & & 5 \\
\hline Singapore & & 16 \\
\hline United Arab Emirates & & 12 \\
\hline Total & & 49 \\
\hline Bahrain & 2001 & 8 \\
\hline Kuwait & & 6 \\
\hline Qatar & & 7 \\
\hline Singapore & & 12 \\
\hline United Arab Emirates & & 12 \\
\hline Total & & 45 \\
\hline Bahrain & 2002 & 6 \\
\hline Kuwait & & 6 \\
\hline Qatar & & 6 \\
\hline Singapore & & 8 \\
\hline United Arab Emirates & & 12 \\
\hline Total & & 38 \\
\hline Bahrain & 2003 & 4 \\
\hline Grand Total & & 252 \\
\hline
\end{tabular}


Figure 1. Conventional Indicators of Bank Performance, 1997-2002
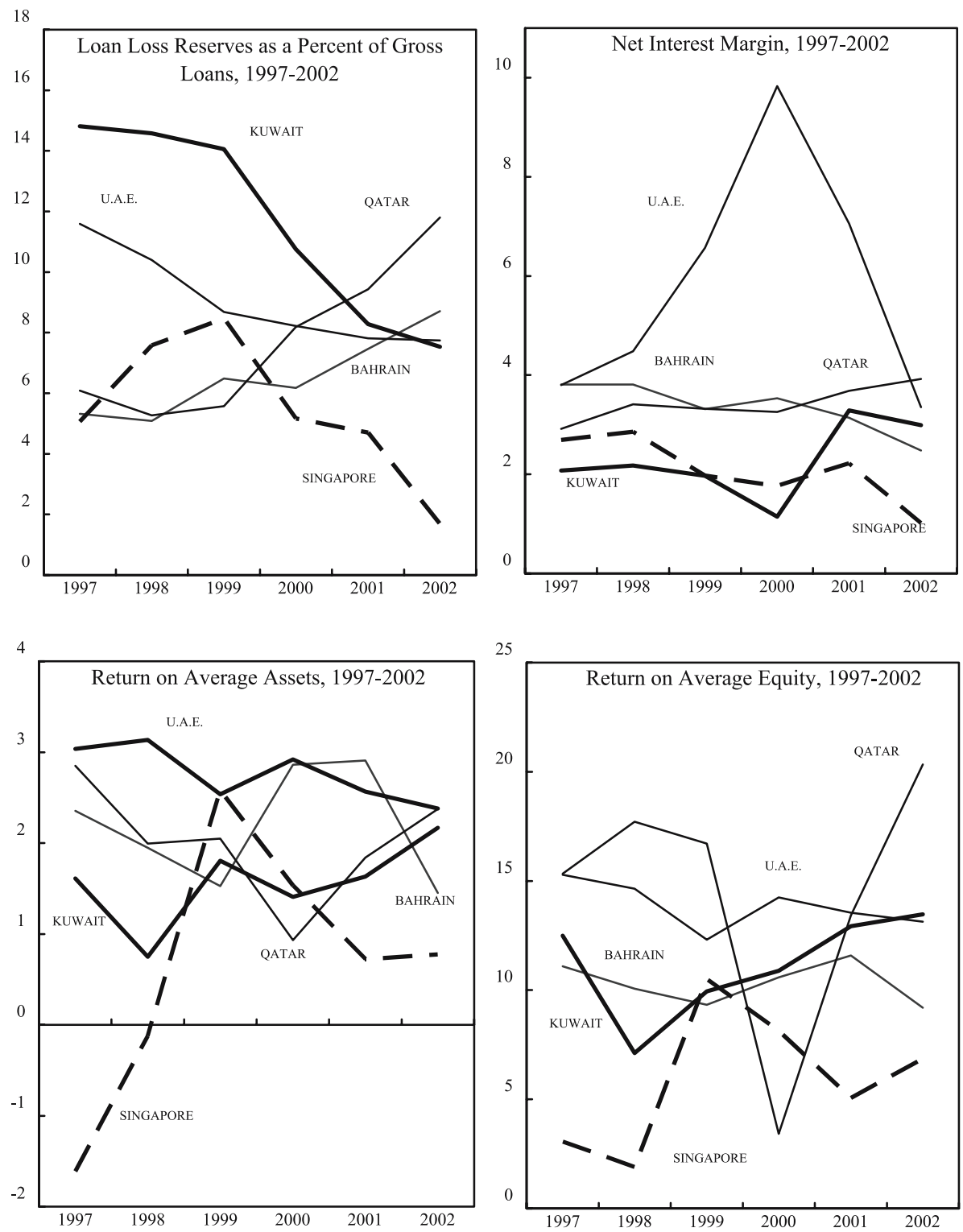

Source: BankScope

hypothesized above. Based on average overall indexes for 1997-2003, banks in 
Table 2: Number of Efficient Sample Banks by Country and Year 1/

\begin{tabular}{llllllll}
\hline & 1997 & 1998 & 1999 & 2000 & 2001 & 2002 & 2003 \\
\hline Bahrain & 0 & $0(1)$ & 1 & 2 & $0(1)$ & 1 & $1(2)$ \\
Kuwait & 0 & 0 & 0 & 0 & 0 & 0 & $\ldots$ \\
Qatar & 0 & 0 & 0 & 0 & 0 & 1 & $\ldots$ \\
United Arab Emirates & 0 & 1 & 0 & 0 & 0 & 2 & $\ldots$ \\
Singapore & 1 & $1(2)$ & 2 & $0(1)$ & $3(4)$ & 4 & $\ldots$ \\
\hline
\end{tabular}

$1 /$ Number of banks with OTE $=1$. Numbers in parentheses represent

the number of banks with OTE $>0.9$, if different from

number of banks with $\mathrm{OTE}=1$.

Bahrain could be 43 percent more cost effective (i.e., use less inputs to produce the same amount of output, as their most efficient counterparts). That number for (a shorter period of) 1997-2002 for the United Arab Emirates and Qatar are 47 and 46 percent, respectively.

Third, relative performance of sample banks by countries is not uniform across the efficiency measures (panels 2 and 3 of Figure 2). Even though banks in GCC countries appear to lag behind their Singaporean counterparts in terms of overall efficiency, the results for the United Arab Emirates, Bahrain, and Qatar appear to be at least as strong if measured by the SE index. Hence, the U.A.E. banks produce an average SE index of 0.87 for 1997-2002, while those in Singapore generate an average index of 0.81. The averages for Bahrain, Qatar, and Kuwait are equal to 0.83, 0.84, and 0.68, respectively.

Fourth, in terms of absolute performance, the inefficiencies seem to be largely caused by purely technical inefficiencies and to a lesser extent by scale inefficiencies (i.e., banks operating either on the increasing or decreasing returns to scale portion of their underlying production functions). The average SE index for the sample banks in Bahrain for 1997-2003 is 0.83, while the PTE index is equal to 0.70 .

Fifth, at least when it comes to the PTE index, there is a trend improvement for all sample countries, reducing the main source of inefficiency. This is largely consistent with new across-the-board developments in the information technology area and of new banking instruments and products (since the trend holds for all countries in the region), but also possibly through countryspecific policies and developments (such as larger marginal impacts of capital account and financial sector liberalization, since some countries, such as Qatar and the United Arab Emirates, register growth rates well in excess of those in 
Figure 2. Cross Country Comparison of Efficiency Indexes, 1997-2003
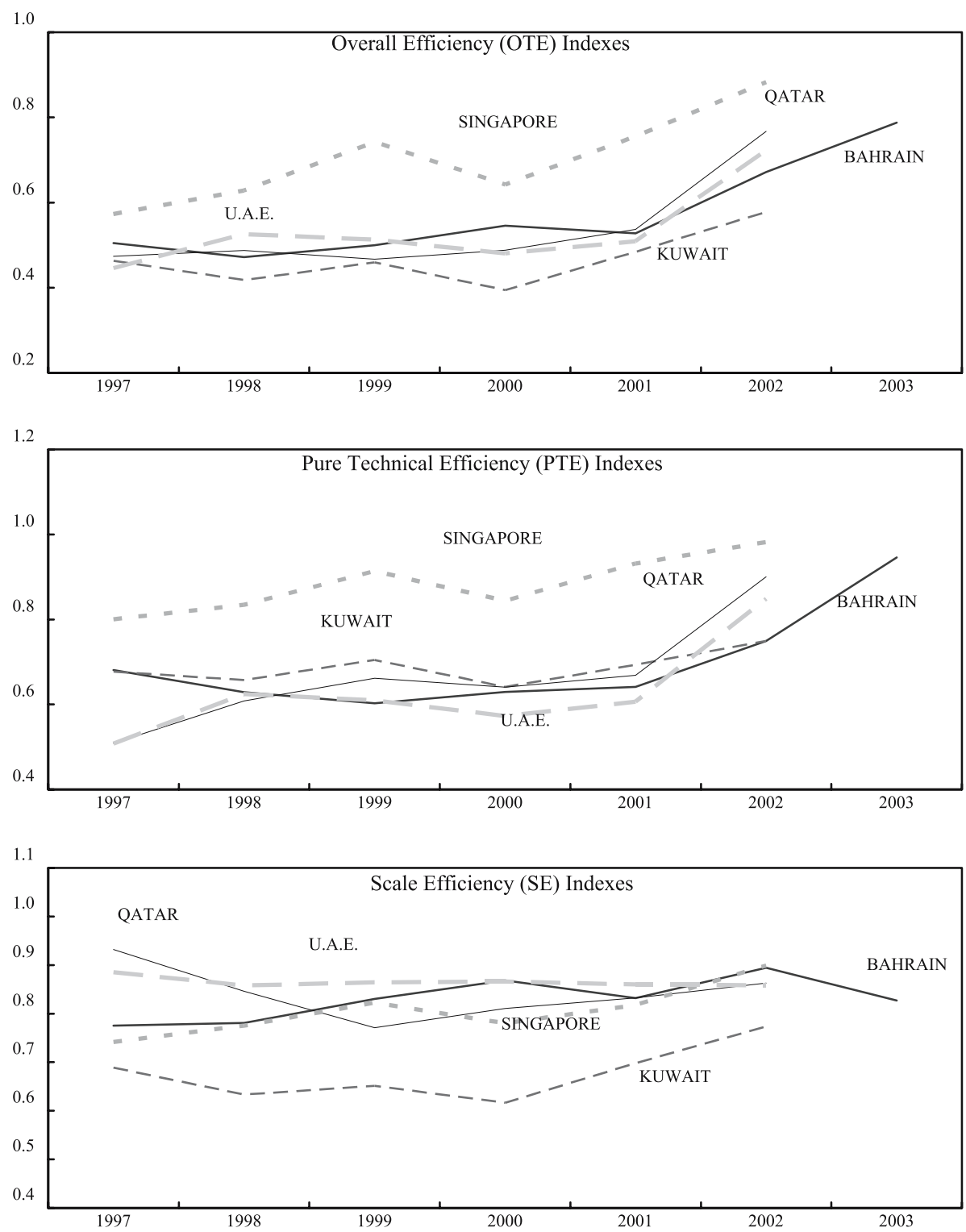

Source: own calculations.

Singapore). 
Table 3: Distribution of Efficiency Indexes by Types of Banks

\begin{tabular}{lllll}
\hline & OTE & PTE & SE \\
\hline \multirow{4}{*}{ Conventional Banks Maximum } & 0.54 & 0.69 & 0.80 \\
& Minimum & 0.33 & 0.43 & 0.50 \\
& St. Deviation & 0.19 & 0.22 & 0.17 \\
Islamic Banks & Average & 0.57 & 0.61 & 0.91 \\
& Maximum & 1.00 & 1.00 & 1.00 \\
& Minimum & 0.30 & 0.37 & 0.57 \\
& St. Deviation & 0.27 & 0.24 & 0.14 \\
& T-test 1/ & 0.11 & -0.31 & 0.66 \\
\hline
\end{tabular}

$1 /$ Test for equal sample averages across conventional and Islamic banks.

Sixth, as indicated in Table 3, there appears to be no statistically significant difference between efficiency indicators for conventional and Islamic banks.

\subsection{Robustness Tests}

To check the robustness of the above results, a test on a sub-sample of Bahraini and Singaporean banks was performed. In addition to limiting the sample to only two countries, the number of inputs and outputs was reduced to two. These now include fixed assets and interest expenditures as inputs, and revenues and liquid assets as outputs.

The results plotted on Figure 3 provide a solid consistency check for the DEA results discussed earlier. The relative pattern between the average Singaporean and Bahraini banks is preserved, and so is the breakdown of the overall efficiency index between pure technical and scale efficiencies. However, the analysis also suggests that once loans are excluded as an output and personnel expenditures excluded as an input, the gap between efficiency indexes among the sample of Singaporean and Bahraini banks declines. Generally this could imply a combination of: (i) inefficiencies related to scope of operations/products (in this case, loans) or (ii) inefficiencies related to use of inputs (in this case, employment resources). Both of these could have policy implications for Bahrain as they are likely to be a result of: (i) relatively large share of nonperforming loans (and as a result low net loan amounts) as well as the relative unattractiveness of loans as products, or (ii) a combination of inefficient use of labor and high wages and benefits. ${ }^{11}$

\footnotetext{
${ }^{11}$ Unfortunately, the available data do not allow us to differentiate between the price
} 


\section{Conclusions}

The linear programming technique and the results presented above provide a useful framework for analyzing Bahrains banking sector performance and its competitiveness in the regional context. Although the simulations suggest that Bahrain occupies a front-runner position among the sample GCC countries, they also reveal that: (i) as expected, banks in Bahrain still lag behind their Singaporean counterparts, and (ii) there is strong competition from other countries in the region. The paper also finds that in terms of scale efficiency, banks in Bahrain operate at the same level as banks in Singapore and their closest competitors in Qatar and the United Arab Emirates. The results appear to be robust with respect to changes in the sample size and model specifications.

Further analysis would be required to pinpoint the exact type of inefficiencies in the sector, by looking at, among other things, the product mix and scope inefficiencies present in the banking sector in Bahrain. It will also be useful from the policymakers perspective to look at the underlying sources of differences in performance among banks across countries, such as macroeconomic and prudential environments, size and concentration of the sector, banks ownership structure, and other institutional factors. ${ }^{12}$ Follow-up studies should focus on the differences across these categories among GCC countries, Bahrains main competitors. Sustaining regional competitiveness would require continuous streamlining of regulatory restrictions, entry and exit rules, and collateral-related bureaucratic practices to limit their potential detrimental effect on banking efficiency. Optimal architecture of the banking sector would also require regional and international integration to guarantee transfers of new skills and technology through competitive pressures and the search for more profits.

and the quantity of inputs used (in this case labor), thus limiting our inferences about the efficiency of their use only to the overall value.

${ }^{12}$ See Grigorian and Manole (2006) for an application of this approach in the case of banks from 17 East European transition countries. 


\section{References}

Alam, I.M.S., (2001.) A non-parametric approach for assessing productivity dynamics of large banks. J. Money, Credit, Banking 33, 121-139.

Al-Hassan, A., Khamis, M., and Oulidi, N. (2010.) The Gulf Cooperation Council (GCC) banking sector: topography and analysis, Banks and Bank Systems, Volume 5, Issue 3, 2010.

Ataullah, A., and Le, H. (2006.) Economic reforms and bank efficiency in developing countries: the case of the Indian banking industry, Applied Financial Economics, Volume 16, Number 9.

Ataullah, A.,Cockerill, T. and Le, H. (2004.) Financial liberalization and bank efficiency: a comparative analysis of India and Pakistan, Applied Economics, 2004, 36, 1915-1924

Banker, R.D., Charnes, A., Cooper, W.W., (1984.) Some Models for Estimating Technical and Scale Inefficiencies in Data Envelopment Analysis. Management Science 30, 1078-1092.

Bergendahl G., (1998.) DEA and Benchmarks - An Application to Nordic Banks, Annals of Operations Research 82, 233-249.

Berger A. N., Humphrey, D. B., (1997.) Efficiency of Financial Institutions: International Survey and Directions for Future Research. European Journal of Operational Research 98, no. 2, 175-212.

Casu B, Molyneux P. (2003.) A comparative study of efficiency in European banking Applied Economics 35 (17): 1865-1876.

Charnes A, Cooper, W. W., Rhodes, E., (1978.) Measuring the Efficiency of Decision Making Units. European Journal of Operations Research, no. 2, 429-44.

Cook, W. D and Zhu, J. (2005.) Modeling performance measurement: Applications and implementation issues in DEA. Springer, New York.

Cooper, W. W., Seiford, L., M; Zhu, J.. (2004.) Handbook on data envelopment analysis. Kluwer Academic, International Series in Operations Research and Management Science. Boston; Dordrecht and London.

Fre, R., Grosskopf, S., Lovell, C.A. K., (1985.) The Measurement of Efficiency of Production, Kluwer Academic Publishing, Boston, MA.

Farrell, M. J., (1957.) The Measurement of Profit Efficiency. Journal of the Royal Statistical Society, Series A, CXX, Part 3, 253-290.Grigorian, D. andManole, V., 2006. Determinants of Commercial Bank Performance in Transition: An Application of Data Envelopment Analysis, Comparative Economic Studies, 48: 497-522.

Isik, I. and M. K. Hassan, (2003.) Financial deregulation and total factor productivity change: An empirical study of Turkish commercial banks, Journal of Banking 
E) Finance 27 (2003) 1455-1485.

Limam, I. (2001.) A Comparative Study of GCC Banks Technical Efficiency, Economic Research Forum, Working Paper 0119, 2001, Cairo, Egypt.

Lozano-Vivas, A., Pastor, J.T. and Iftekhar, H. (2001.), European Bank Performance Beyond Country Borders: What Really Matters? European Finance Review 5: 141165.

Maghyereh, A. (2004.) The Effect of Financial Liberalization on the Efficiency of Financial Institutions: The Case of Jordanian Commercial Banks. Journal of Transnational Management Development. Vol. 9 (2-3). p 71-106.

Murillo-Zamorano L.R. (2004.) Economic efficiency and frontier techniques, Journal of Economic Surveys, 18 (1): 33-77.

Ozkan-Gunay, E.N. and Tektas, A. (2006.), Efficiency Analysis of the Turkish Banking Sector in Precrisis and Crisis Period: A DEA Approach, Contemporary Economic Policy, Vol. 24, No. 3, July 2006, 418-431

Rezvanian, R., Mehdian, S., (2002.) An Examination of Cost Structure and Production Performance of Commercial Banks in Singapore. Journal of Banking and Finance, vol. 26, 79-98.

Saad, W. and EL Moussawi, C. (2006.) Efficiency Analysis of the Banking Sector in Kuwait. Journal of Development 85 Economic Policies. Vol. 8 (2). p 37-65. June 2006.

Stavarek D. (2006.) Banking efficiency in the context of European integration. Eastern European Economics 44 (4): 5-31.

van Ark, B., Frankema, E., Manole, V. and Tank, A., (2008.) Growing Beyond Oil Productivity, Performance, and Progress in the Countries of the Gulf Cooperation Council, The Conference Board, Research Report R-1426-08-RR.

Wheelock, D.C., Wilson, P.W., (1999.) Technical progress, inefficiency, and productivity change in US banking, 1984-1993. J. Money, Credit, Banking 31, 212-234. 
Figure 3. A Robustness Test: Two-Input-Two-Output Case

(Sample includes banks in Bahrain and Singapore, 1997-2002)
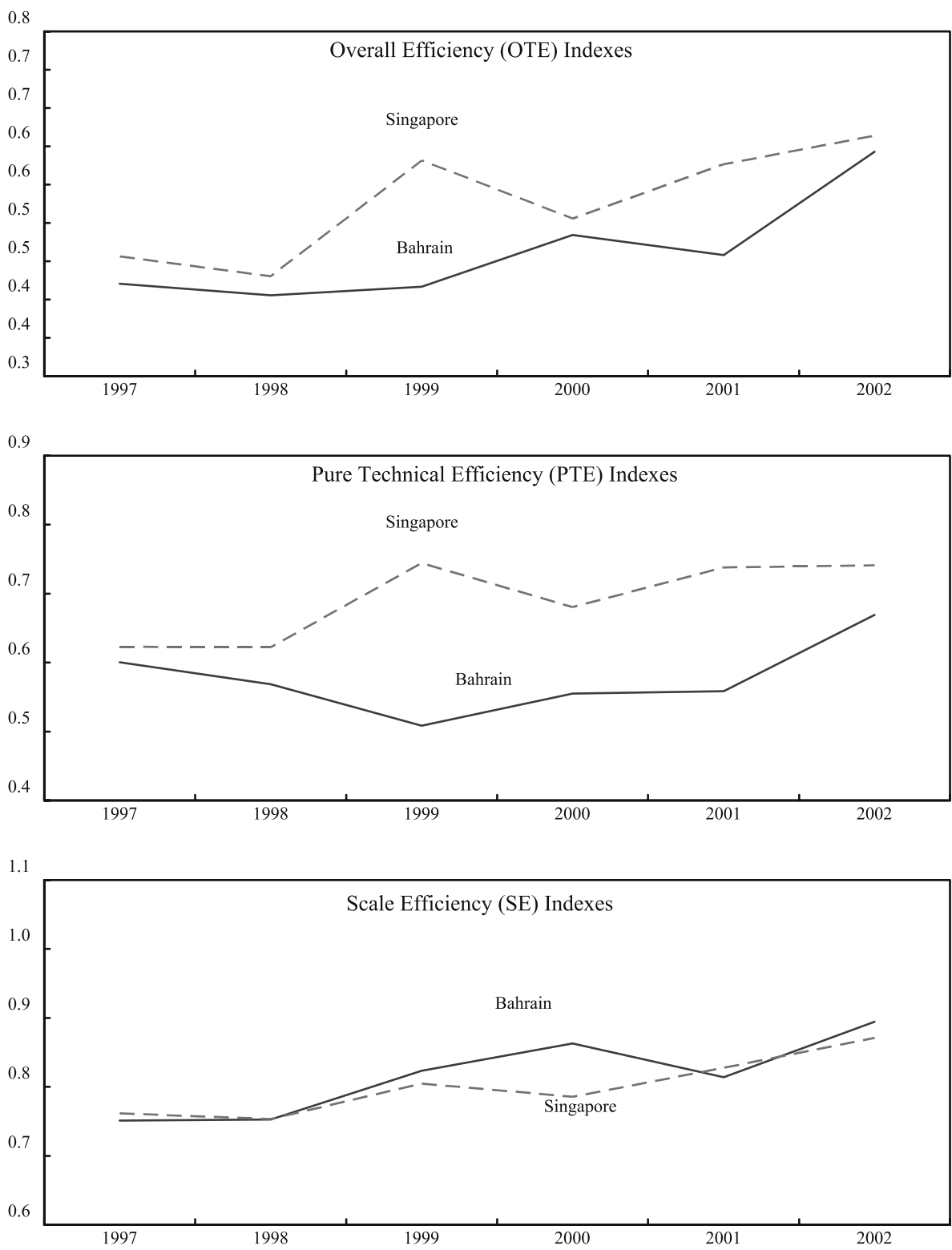

Source: own calculations. 